\title{
REVIEW
}

\section{Low Carbohydrate Diets and Type 2 Diabetes: What is the Latest Evidence?}

Pamela Dyson

To view enhanced content go to www.diabetestherapy-open.com

Received: June 25, 2015 / Published online: October 7, 2015

(c) The Author(s) 2015. This article is published with open access at Springerlink.com

\section{ABSTRACT}

Introduction: Low carbohydrate diets are again in the spotlight and have been identified as particularly appropriate for people with type 2 diabetes. There is confusion amongst both health professionals and people with diabetes about the suitability of these diets. This review aims to provide an overview of the latest evidence and to explore the role of low carbohydrate diets for people with type 2 diabetes.

Methods: An electronic search of English language articles was performed using MEDLINE (2010-May 2015), EMBASE (2010-May 2015), and the Cochrane Central Register of Controlled Trials (2010-May 2015). Only randomized controlled trials comparing interventions evaluating reduced carbohydrate intake with higher carbohydrate intake in people with diagnosed type 2 diabetes were included. Primary outcomes included weight, glycated hemoglobin, and lipid concentrations.

\section{P. Dyson $(\bowtie)$}

Churchill Hospital, University of Oxford, OCDEM, Oxford, UK

e-mail: pamela.dyson@ocdem.ox.ac.uk
Results: Low carbohydrate diets in people with type 2 diabetes were effective for short-term improvements in glycemic control, weight loss, and cardiovascular risk, but this was not sustained over the longer term. Overall, low carbohydrate diets failed to show superiority over higher carbohydrate intakes for any of the measures evaluated including weight loss, glycemic control, lipid concentrations, blood pressure, and compliance with treatment.

Conclusion: Recent studies suggest that low carbohydrate diets appear to be safe and effective over the short term, but show no statistical differences from control diets with higher carbohydrate content and cannot be recommended as the default treatment for people with type 2 diabetes.

Keywords: Cardiovascular risk; Glycemic control; Low carbohydrate diet; Type 2 diabetes; Weight loss

\section{INTRODUCTION}

Diabetes mellitus has long been considered a disease of carbohydrate metabolism, and before the discovery of insulin in 1921, low 
carbohydrate starvation diets were the default treatment [1]. From the 1930s through to the 1960s, many experts continued to advise strict carbohydrate restriction, with the result that most people with diabetes adopted a high fat, low carbohydrate diet [2]. However, some early work in the 1920s and 1930s had suggested that high carbohydrate diets improved glucose tolerance, and the dramatic increase in deaths from vascular disease in those whose lives were prolonged by insulin treatment led to a volte-face in the 1980s, with authorities now recommending low fat, high carbohydrate diets [3]. The pendulum has again swung the other way, and there is renewed interest in very low carbohydrate diets for the treatment of diabetes, with various physicians extolling the virtues of dietary carbohydrate restriction as the first approach in diabetes management [4], and some authorities recognizing low carbohydrate diets as a suitable weight-loss strategy for those with type 2 diabetes $[5,6]$.

Interestingly, the carbohydrate debate seems to be based on strong personal opinion and those working in the area tend to cherry-pick the evidence to support their particular view, whether that of low, moderate, or high carbohydrate. Debates about the issue can become very passionate, and it is worth reminding ourselves that "passion in science is an infallible marker of lack of evidence" [3]. The evidence available is contradictory at best, and leaves both health professionals and people with diabetes alike wondering if low carbohydrate diets do live up to the hype surrounding them, and whether they should be recommended as a suitable treatment. Recent systematic reviews and meta-analyses including people with type 2 diabetes report that although low carbohydrate diets lead to significantly greater weight loss and improvements in glycated hemoglobin
(HbA1c) and lipids over the short term $[7,8]$, there is no greater advantage over the longer term $[9,10]$. Despite this evidence, low carbohydrate diets remain an area of controversy and this review aims to provide an overview of the latest evidence, and to explore the role of low carbohydrate diets for people with type 2 diabetes. This article is based on previously conducted studies, and does not involve any new studies of human or animal subjects conducted by the author.

\section{DEFINITION OF LOW CARBOHYDRATE DIETS}

One of the issues with the term "low carbohydrate" is uncertainty about what this means in terms of carbohydrate intake. Ketosis readily occurs at carbohydrate intakes below $50 \mathrm{~g} /$ day [11], and these very low carbohydrate, ketogenic diets (VLCKD) appear to have more pronounced effects than other, less restricted carbohydrate diets [12]. The taxonomy for diets containing various amounts of dietary carbohydrate has been suggested in a recent paper [4], see Table 1. In practice, most Atkins-style diets are designed to be very low in carbohydrate (less than $20 \mathrm{~g}$ /day initially) and high in protein and fat [13], and other diets, e.g., the Zone [14] and the South Beach Diet [15], promote a moderate carbohydrate restriction together with high protein and low fat intakes.

\section{The Role of Low Carbohydrate Diets in Treating Type 2 Diabetes}

Treating type 2 diabetes is challenging, encompassing as it does management of glycemia, cardiovascular disease (CVD) risk factors, obesity, and other co-morbidities by a 
Table 1 Taxonomy of diets containing differing amounts of carbohydrate

\begin{tabular}{lll}
\hline Description & Amount of carbohydrate & \\
\cline { 2 - 3 } & g/day & \% total energy intake \\
\hline Very low carbohydrate ketogenic diet & $20-50$ & $\leq 10$ \\
Low carbohydrate & $<130$ & $<26$ \\
Moderate carbohydrate & $130-230$ & $26-45$ \\
High carbohydrate & $>230$ & $>45$ \\
\hline
\end{tabular}

Adapted from Feinman et al. [4]

combination of lifestyle strategies (diet and physical activity), behavioral and psychological interventions, pharmaceutical treatment, and bariatric surgery. Medical management of type 2 diabetes has led to cynicism about the efficacy of lifestyle management, particularly dietary strategies, and at present the components of the most effective diet remain unknown. A recent systematic review and meta-analysis suggested that low carbohydrate, low glycemic index (GI), Mediterranean, and high protein diets all showed greater improvements in glycemic control than control diets [16]. Despite criticism of the statistical analysis due to heterogeneity of the studies included [17], this review supports the premise that improvements in glycemic control, CVD risk, and weight loss are achievable with different diets with varying amounts of carbohydrate, and that low carbohydrate diets are not necessarily superior in effect.

\section{METHODS}

This present review includes recent studies published since 2010. An electronic search of English language articles was performed using MEDLINE (2010-May 2015), EMBASE (2010-May 2015), and the Cochrane Central
Register of Controlled Trials (2010-May 2015) using the search terms "low carbohydrate diet" and "type 2 diabetes". The selection criteria included all randomized controlled trials (RCTs) comparing interventions evaluating reduced carbohydrate intake with higher carbohydrate intake in people with diagnosed type 2 diabetes. Primary outcomes included weight, HbA1c, and lipid concentrations.

The title and abstract of each record retrieved from the search were screened by the author (PAD), and full articles were retrieved if the information given suggested that the study met the selection criteria. Data were extracted using a specially designed form and included information about authors, country, year of publication, primary and secondary outcomes, intervention, and outcomes.

\section{RESULTS}

From 253 search results, 21 articles were retrieved for assessment of eligibility. Thirteen of these studies were excluded and eight met the inclusion criteria [18-25]. The flow diagram illustrating the search and selection of studies is shown in Fig. 1. A descriptive summary of the included trials and main results are shown in Tables 2, 3, and 4. It proved impossible to combine the results of the eight selected 


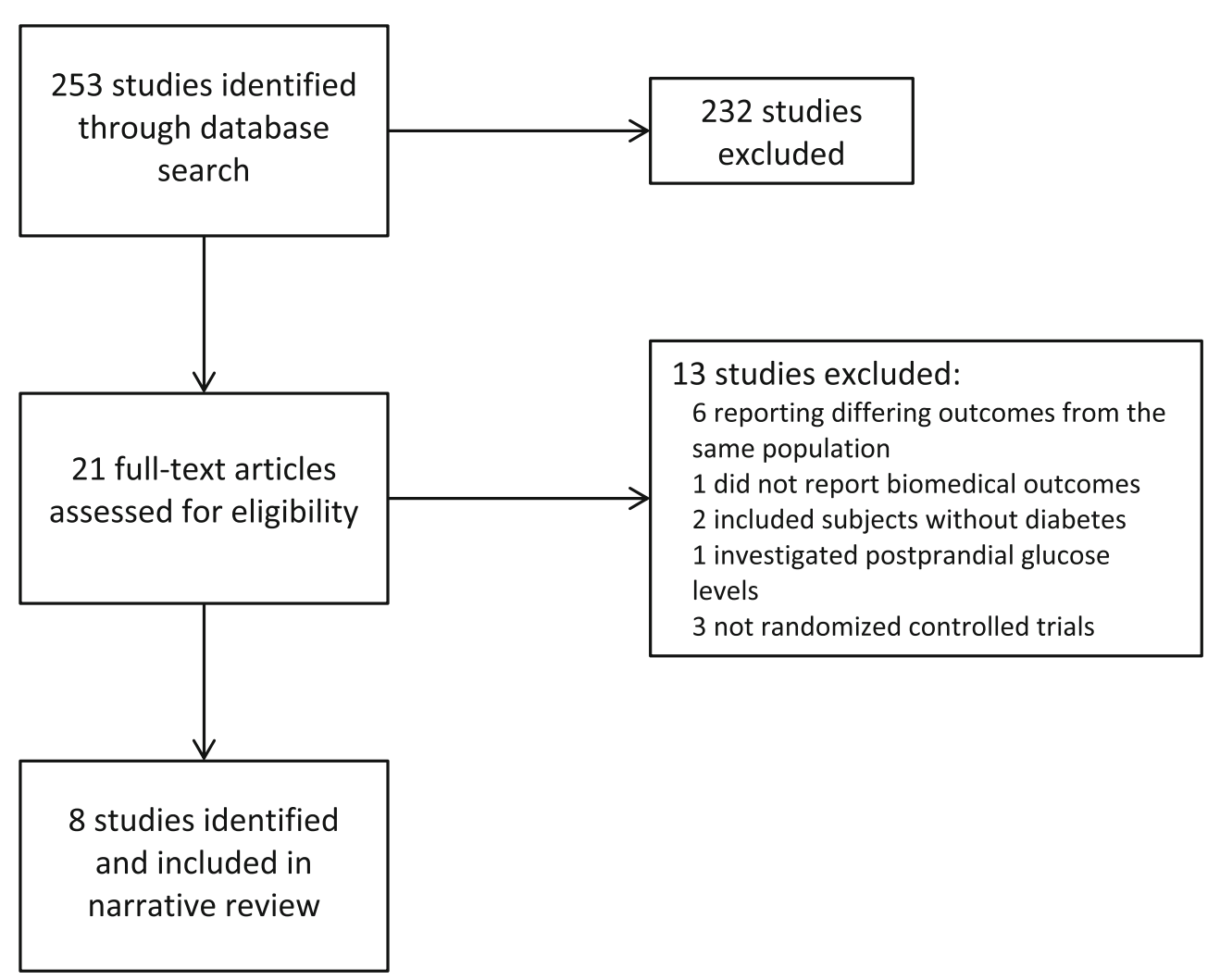

Fig. 1 Study flow diagram showing number of studies screened, assessed for eligibility, and included in the narrative review

studies using statistical methods as the studies were heterogeneous in terms of the dietary intervention (carbohydrate intakes ranged from more than $20 \mathrm{~g}$ to $166 \mathrm{~g} /$ day), length of follow-up (6-24 months), data quality, and data reporting. For this reason a narrative review was undertaken.

\section{Weight Loss}

All eight studies reported weight loss in the group receiving the reduced carbohydrate intervention, with mean weight losses ranging from $1.7 \mathrm{~kg}$ [18] to $12.0 \mathrm{~kg}$ [25]. The greatest weight loss was reported in the shortest study lasting 6 months [25]. There appeared to be no relationship between degree of carbohydrate restriction and weight loss. However, these studies all included a control group receiving dietary interventions that provided higher carbohydrate intakes but were designed for weight loss, consequently those in the control groups also lost weight during the course of the studies. Mean weight losses in the control group were similar to those in the reduced carbohydrate group and ranged from $0.2 \mathrm{~kg}$ [18] to $11.5 \mathrm{~kg}$ [25], with the result that none of the eight studies reported significantly greater weight loss in the group receiving the reduced carbohydrate intervention.

\section{Glycemic Control}

Despite no significant differences in weight losses, three of the studies reported significantly greater reductions in $\mathrm{HbA1c}$ in the reduced carbohydrate intervention group $[19,23,24]$. One of the studies did not report 


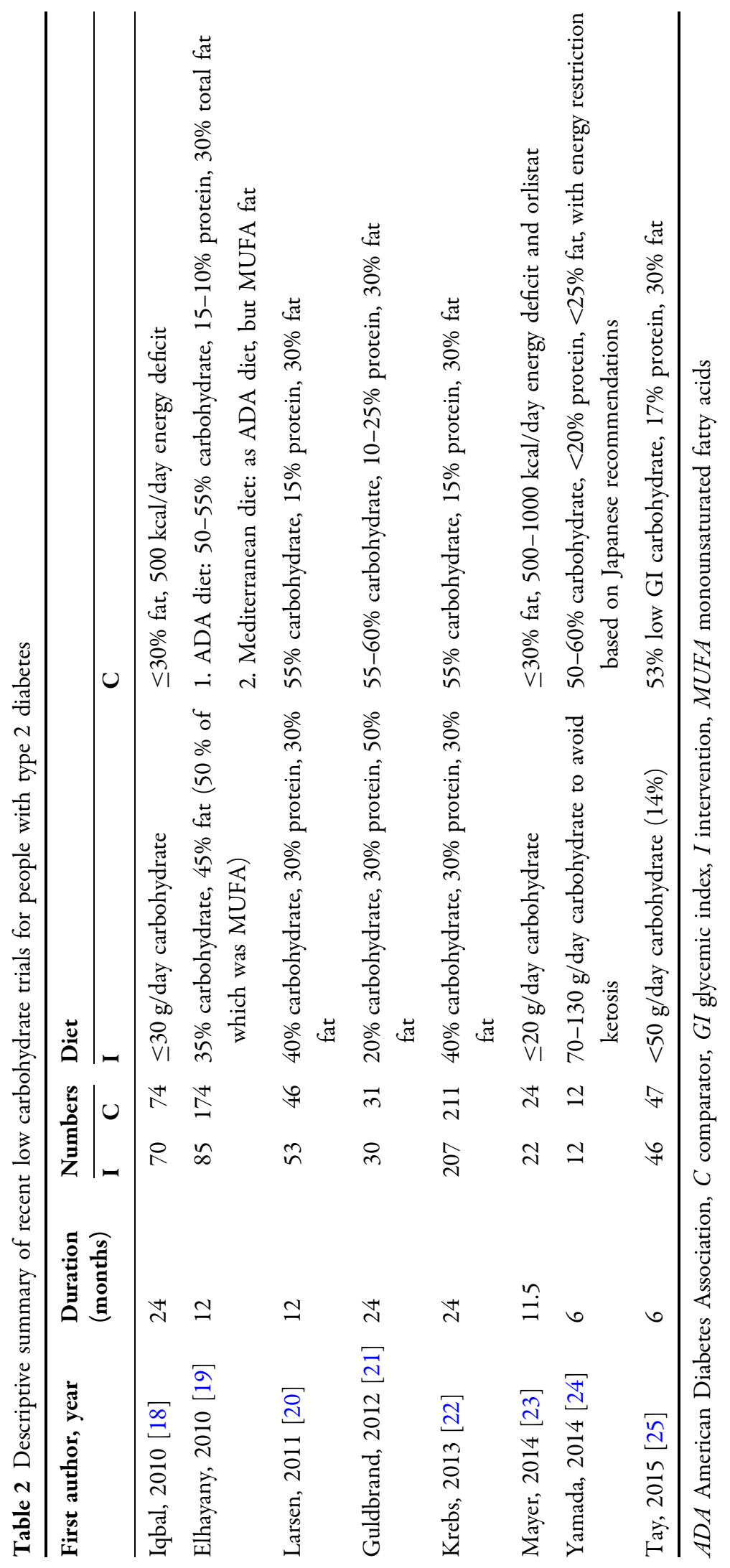


Table 3 Summary of results of recent low carbohydrate trials for people with type 2 diabetes (body weight and glycemic control)

\begin{tabular}{|c|c|c|c|c|c|c|c|c|}
\hline \multirow[t]{2}{*}{ First author, year } & \multicolumn{4}{|c|}{ Body weight loss (kg) } & \multicolumn{4}{|c|}{ Changes in HbAlc (\%) } \\
\hline & I & $\mathbf{C}$ & $\mathbf{I}-\mathbf{C}$ & $P$ value & $\bar{I}$ & $\mathbf{C}$ & $\mathbf{I}-\mathbf{C}$ & $P$ value \\
\hline Iqbal, 2010 [18] & 1.7 & 0.2 & 1.2 & 0.29 & -0.1 & -0.2 & -0.1 & NS \\
\hline Elhayany, 2010 [19] & 8.9 & 7.6 & 1.4 & 0.557 & -2.0 & -1.6 & -0.4 & 0.88 \\
\hline Larsen, $2011[20]$ & 2.23 & 2.17 & 0.07 & 0.9 & -0.23 & -0.28 & 0.04 & 0.76 \\
\hline Guldbrand, 2012 [21] & 2.0 & 2.9 & -0.9 & 0.33 & 0.0 & 0.2 & -0.2 & 0.76 \\
\hline Krebs, 2013 [22] & 3.9 & 6.0 & -2.1 & 0.73 & 0.1 & 0.1 & 0.0 & 0.5 \\
\hline Mayer, 2014 [23] & 7.5 & 8.1 & -0.6 & 0.8 & -0.7 & 0.2 & -0.8 & 0.045 \\
\hline Yamada, 2014 [24] & 2.6 & 1.4 & 1.2 & 0.8 & -0.6 & 0.2 & -0.4 & 0.03 \\
\hline Tay, 2014 [25] & 12.0 & 11.5 & 0.5 & 0.57 & NR & NR & NR & NR \\
\hline
\end{tabular}

$C$ comparator, HbAlc glycated hemoglobin, $I$ intervention, $N R$ not reported, $N S$ no significant difference

HbA1c [25] despite the fact that this measurement was defined as the primary outcome, leading to the speculation that there were no differences in glycemic control between the two groups [26]. This has now been confirmed, with recent publication of a follow-up at 12 months reporting no difference in $\mathrm{HbA1c}$ reductions between the low and high carbohydrate intakes [27]. Changes in HbA1c in the reduced carbohydrate intervention groups were variable between studies, ranging from $+0.1 \%$ [22] to $-2.0 \%$ [19], with the greatest reduction seen in studies of shorter duration. There appeared to be little correlation between the degree of carbohydrate restriction and changes in glycemic control. HbA1c levels were also reduced in five of the seven control groups, with changes ranging from $+0.1 \%$ [22] to $-0.3 \%$ [20]. In summary, one study failed to report HbA1c [25], three studies showed significant reductions in $\mathrm{HbA1c}$ in the reduced carbohydrate group [19, 23, 24], and four studies showed no significant differences between the two groups [18, 20-22].

\section{Cardiovascular Risk}

Cardiovascular risk was assessed by changes in lipid concentrations and blood pressure. All eight studies measured lipid concentrations, and seven studies measured blood pressure [18, 20-25]. Most studies reported reductions in lipid concentrations in both the reduced carbohydrate intervention and higher carbohydrate control group, with no significant differences between the two groups. However, significantly greater reductions in the reduced carbohydrate group were reported for total cholesterol concentrations in one study [22], low density lipoprotein (LDL) and high density lipoprotein (HDL) concentrations in one study [19], and triglycerides in three studies [19, 22, 25]. Changes in blood pressure were variable and showed no significant differences in six of the seven studies reporting outcomes; four studies reported reductions in systolic blood pressure (SBP) in the reduced carbohydrate group compared to the higher carbohydrate group [18, 20, 23, 25], and three 
Table 4 Summary of results of recent low carbohydrate trials for people with type 2 diabetes (cardiovascular risk)

\begin{tabular}{|c|c|c|c|c|c|c|c|c|c|c|c|c|}
\hline \multirow[t]{2}{*}{$\begin{array}{l}\text { First } \\
\text { author, year }\end{array}$} & \multicolumn{2}{|c|}{$\begin{array}{l}\text { Total } \\
\text { cholesterol } \\
(\mathrm{mmol} / \mathrm{L})\end{array}$} & \multicolumn{2}{|c|}{$\begin{array}{l}\text { HDL } \\
(\mathbf{m m o l} / \mathbf{L})\end{array}$} & \multicolumn{2}{|c|}{$\begin{array}{l}\text { LDL } \\
(\mathbf{m m o l} / \mathbf{L})\end{array}$} & \multicolumn{2}{|c|}{$\begin{array}{l}\text { Triglycerides } \\
(\mathbf{m m o l} / \mathrm{L})\end{array}$} & \multicolumn{2}{|c|}{$\begin{array}{l}\text { Systolic BP } \\
(\mathrm{mm} / \mathbf{H g})\end{array}$} & \multicolumn{2}{|c|}{$\begin{array}{l}\text { Diastolic BP } \\
(\mathrm{mm} / \mathrm{Hg})\end{array}$} \\
\hline & $\mathrm{I}-\mathrm{C}$ & $P$ value & $\mathrm{I}-\mathrm{C}$ & $P$ value & $\mathrm{I}-\mathrm{C}$ & $P$ value & $\mathrm{I}-\mathrm{C}$ & $P$ value & $\mathrm{I}-\mathrm{C}$ & $P$ value & $\mathrm{I}-\mathrm{C}$ & $P$ value \\
\hline $\begin{array}{l}\text { Iqbal, } 2010 \\
{[18]}\end{array}$ & 0.03 & NS & 0.0 & NS & -0.06 & NS & -0.14 & NS & -6.7 & NS & 0.5 & NS \\
\hline $\begin{array}{l}\text { Elhayany, } \\
2010[19]\end{array}$ & -0.02 & 0.204 & 0.18 & $<0.001$ & -0.24 & 0.036 & -0.64 & $<0.001$ & NR & NR & NR & NR \\
\hline $\begin{array}{l}\text { Larsen, } 2011 \\
\quad[20]\end{array}$ & -0.16 & 0.32 & 0.01 & 0.84 & -0.01 & 0.3 & -0.17 & 0.34 & -4.3 & 0.05 & -0.4 & 0.7 \\
\hline $\begin{array}{l}\text { Guldbrand, } \\
2012[21]\end{array}$ & 0.2 & 0.33 & 0.12 & 0.15 & 0.0 & 0.16 & 0.1 & 0.35 & 2 & 0.74 & 3 & 0.75 \\
\hline $\begin{array}{l}\text { Krebs, } 2013 \\
\text { [22] }\end{array}$ & -0.07 & 0.03 & 0.01 & 0.41 & 0.03 & 0.32 & -0.03 & 0.02 & 1 & 0.87 & 0.0 & 0.96 \\
\hline $\begin{array}{l}\text { Mayer, } 2014 \\
{[23]}\end{array}$ & 0.23 & 0.4 & 0.03 & 0.5 & 0.25 & 0.3 & -0.28 & 0.3 & -11 & 0.006 & -6 & 0.013 \\
\hline $\begin{array}{l}\text { Yamada, } \\
2014 \text { [24] }\end{array}$ & NR & NR & 0.25 & 0.13 & -0.08 & 0.49 & -0.58 & 0.08 & 1.7 & 0.54 & -4.6 & 0.3 \\
\hline $\begin{array}{l}\text { Tay, } 2014 \\
\text { [25] }\end{array}$ & 0.0 & 0.89 & NR & NR & 0.0 & 0.81 & -0.4 & 0.001 & -2.3 & 0.26 & -1.8 & 0.1 \\
\hline
\end{tabular}

$B P$ blood pressure, $C$ comparator, $H D L$ high density lipoprotein, $I$ intervention, $L D L$ low density lipoprotein, $N R$ not reported, $N S$ no significant difference

reported increases [21, 22, 24]; for diastolic blood pressure four reported decreases in the reduced carbohydrate intervention group [18, $20,23,25]$ and three reported increases [21, 22, 24]. In summary, although there was no evidence of a deleterious effect of a reduced carbohydrate diet on CVD risk, equally, there was no evidence of superiority over a higher carbohydrate intake.

\section{Adherence and Attrition}

Adherence to the prescribed intervention was assessed by self-reported dietary intake using a variety of methods including 24-hour diet histories and 3-, 4-, and 7-day food diaries. In the majority of the studies, mean intake of carbohydrate in the reduced carbohydrate intervention group was higher than that prescribed; in only two studies did the participants achieve target intakes [24, 25]. Attrition rates were reported for seven studies, and ranged from no dropouts [24] to $60 \%$ [18]. There were no differences in attrition rates between the intervention and control groups in any of the studies. In general, lower attrition rates were reported for shorter studies, and for those with fewer participants.

\section{DISCUSSION}

This review of recent studies evaluating the effects of low carbohydrate diets in people with 
type 2 diabetes supports previous meta-analyses showing that although there may be greater short-term improvements in glycemic control, weight loss, and CVD risk, this is not sustained over the longer-term. Many studies have attempted to determine the ideal macronutrient (protein, fat, and carbohydrate) intake for people with type 2 diabetes, and evidence to date is inconclusive [28]. One of the best predictors of improved outcomes in people with type 2 diabetes is energy restriction and weight loss, and there are a variety of strategies by which this may be achieved, with no clear indication of the superiority of low carbohydrate diets. This is true for both those with type 2 diabetes [28] and those without [10, $29,30]$. Much of the positive effect of low carbohydrate diets is due to weight loss, and the effect independent of weight change is difficult to assess.

In the absence of categorical evidence supporting the use of low carbohydrate diets, one wonders why they have gained such strong support and media attention over the past few years. Many proponents of low carbohydrate diets maintain that recent healthy eating guidelines promoting carbohydrate and restricting fat have been counterproductive and have led to escalating rates of obesity and type 2 diabetes [31]. The cause of obesity is extremely complex [32] and it is unlikely that one factor, that of carbohydrate intake, is the root cause. There is also contrary evidence indicating that diets high in fruit, vegetables, whole grains, and legumes (all of which contain carbohydrate) actually protect against obesity, CVD, and, to a lesser extent, type 2 diabetes [33]. Studies often fail to address the type of carbohydrate included in the diet, and this may affect outcomes [34]. There is now accumulating evidence that unprocessed carbohydrates, including whole grains, fruit, vegetables, and legumes, have health benefits [35], and those from refined sources, including white bread and white rice and particularly sugar and sugar-sweetened beverages (SSB), are associated with increased risk of obesity, CVD, and type 2 diabetes [36-39]. It could be speculated that the benefits of low carbohydrate diets are associated with a reduction in refined carbohydrate and not total carbohydrate per se. For people with type 2 diabetes, there is evidence from a large, long-term RCT suggesting that higher carbohydrate diets can improve weight loss, glycemic control, and CVD risk factors (although not CVD mortality) [40]. The Look AHEAD trial (ClinicalTrials.gov identifier, NCT0017953) reported greater weight loss, improvements in glycemia and CVD risk factors, and reduced risk of microvascular complications, depression, sleep apnea, and urinary incontinence at 9.6-year follow-up in those allocated an intensive lifestyle education (ILE) program compared to standard diabetes education (DES) [41]. Those in the ILE group were encouraged to increase physical activity and adopt an energy-reduced, low fat, partial meal replacement plan. At 1-year follow-up, they derived a higher proportion of energy from carbohydrate (ILE $50.8 \%$ vs. DES $42.5 \%$ ) and a lower proportion from fat (ILE $34.2 \%$ vs. DES $39.7 \%$ ), demonstrating that a higher carbohydrate, lower fat diet was associated with improved outcomes [42].

\section{Disadvantages of Low Carbohydrate Diets}

Concern has been expressed about the long-term health effects of low carbohydrate diets on renal function, calcium metabolism, lack of essential nutrients, and CVD risk [43], and a systematic review and meta-analysis reported that low carbohydrate diets were 
associated with a significantly higher risk of all-cause mortality [44]. Reductions in carbohydrate intake may also be associated with an increased risk of hypoglycemia in those treated with insulin or insulin secretagogues, and to reduce this medical supervision, reductions in medication and self-monitoring of blood glucose concentrations are recommended for those adopting a low carbohydrate diet.

Low carbohydrate diets tend to be higher in protein, and this may have an adverse effect on renal function [45]. There are very few studies investigating renal function and low carbohydrate diets, although a recent study suggested that improvements in renal function are related to weight loss, and that this occurs to a similar extent with low carbohydrate, Mediterranean, and low fat diets [46]. In obese people without diabetes, studies have shown that low carbohydrate diets have no harmful effects on glomerular filtration rate (GFR), albuminuria, fluid or electrolyte balance when compared to a low fat diet $[47,48]$.

It has been postulated that as very low carbohydrate diets cause ketosis, this induces acidosis, promoting urinary calcium loss and leading to low bone mineral density and increased risk of osteoporosis. There is very little research in this field, and none at all in people with diabetes, making it challenging to draw firm conclusions. One animal study showed that low carbohydrate diets induce low bone mineral density in rats [49], and two small studies in obese subjects reported deleterious effects on urinary calcium loss [47] and markers for bone formation [50]. Conversely, another study reported no effect of a low carbohydrate diet on bone turnover markers [51]. The long-term effects of low carbohydrate diets on calcium metabolism and bone health are unknown.
Other claims about the negative aspects of low carbohydrate diets include that of nutritional deficiencies, namely those commonly found in unprocessed carbohydrate foods including vitamins, minerals, dietary fiber, and phytochemicals with antioxidant properties [52]. There is no evidence to either endorse or refute this suggestion, although a computer-generated analysis showed that low carbohydrate diets are deficient in many micronutrients [53], and an analysis of four popular diets from the USA (Atkins, LEARN, Ornish, and Zone) demonstrated that all diets showed a degree of deficiency: specifically thiamine, folic acid, vitamin C, iron, and magnesium in the case of low carbohydrate diets [54]. Low carbohydrate diets may be low in dietary fiber and epidemiological evidence suggests that low intakes of dietary fiber are associated with increased risk of lower gastrointestinal disorders, including colon cancer $[34,55]$, and this may be further exacerbated by high intakes of red meat and meat products [56].

The most controversial aspect of low carbohydrate diets is that they may increase the risk of CVD as they are associated with higher total and saturated fat intakes. There is little evidence for this in people with type 2 diabetes as there are very few studies; as a result many commentators have extrapolated from studies in the general population. There are some issues with the quality of evidence used to define the relationship between fat intake and CVD risk as most studies are short-term RCTs with surrogate end points, or observational and epidemiological studies, where associations do not prove causation. Recent meta-analyses and systematic reviews have reported that there is no association between CVD and type of dietary fat, whether saturated fatty acids (SFA), polyunsaturated fatty acids (PUFA), or 
monounsaturated fatty acids (MUFA) [57, 58], leading to headlines stating that scientists have been wrong for decades and have mislead the public with low-fat, healthy eating recommendations. However, both these reviews have been widely criticized for omitting important cohort studies, incorrect extraction of data, incorrect interpretation, and a failure to mention the results of other, superior analyses [59]. Many experts still maintain that there is an association between SFA and CVD [60], and that the evidence supports substitution of SFA by unsaturated fat [61]. The recently published Cochrane review also supports this recommendation, stating that there is a small but potentially important reduction in CVD risk with the reduction of SFA [62]. It is worth remembering that most studies examining the relationship between fat intake and CVD include fat intakes in a fairly narrow range of approximately $30-40 \%$ of total energy intake, and little is known about the relative effects of intakes above these values. This may be an issue for some individuals adopting a low carbohydrate diet where fat, often SFA, is actively promoted to induce ketosis and increase palatability. As is the case with glycemic control, weight reduction improves CVD risk factors and if weight loss is achieved, there are no significant differences between either low fat, high carbohydrate diets and low carbohydrate diets for primary prevention of CVD [63]. On balance, there is little evidence to support changing current recommendations for fat intake in people with type 2 diabetes.

There is a further consideration that is now coming to the fore, and that is the challenge of sustainable nutrition. Sustainable diets, as defined by the Food and Agriculture Organization (FAO), are nutritionally adequate, safe, affordable, and culturally acceptable and are sparing of natural and human resources [64]. The carbon footprint of different foodstuffs has been investigated, and the results show that red meat is the most carbon intensive process, followed by dairy, fruit, chicken, and vegetables. Cereals, oils, and sugar are the least carbon intensive [65]. Low carbohydrate diets tend to include foods with the biggest carbon footprint and large-scale adoption of these diets will increase greenhouse gas emissions. In terms of cultural acceptance, proponents of low carbohydrate diets for diabetes could be accused of elitism. Newly industrialized countries such as China and India are experiencing a rapid increase in the prevalence of diabetes [66, 67], and it is estimated that by 2030, 551 billion people (10\% of the world's population) will have diabetes [68]. For many of these people, a low carbohydrate diet is either unacceptable for religious or cultural reasons, or simply unaffordable.

\section{CONCLUSIONS}

To date the evidence suggests that low carbohydrate diets are effective for weight loss and improvements in glycemic control and CVD risk, but that they are not superior to other dietary approaches. For this reason, low carbohydrate diets cannot be recommended as the default strategy for people with type 2 diabetes. However, they are another useful tool for those who wish to adopt them, although long-term side effects of these diets remain unknown.

The question remains-how much carbohydrate should someone with type 2 diabetes eat? Both Diabetes UK and the American Diabetes Association recommend an individualized approach, where health 
professionals work with the person with diabetes to identify an eating pattern that is based on that individual's lifestyle, culture, and preferences. Both authorities identify carbohydrate management as a key strategy and address both type and amount of carbohydrate, emphasizing unprocessed carbohydrate from whole grains, fruit, and vegetable sources.

Perhaps it is time to abandon the macronutrient approach to nutritional advice and begin to talk about specific foods and eating patterns and encourage those associated with health. There is no "ideal" eating pattern that will benefit all people with diabetes, although total energy intake is an important consideration, especially in those who are overweight or obese. Epidemiological and observational studies show that there are dietary patterns that are associated with better overall health outcomes and which are rich in vegetables, fruit, whole grains, seafood, legumes, and nuts, contain moderate amounts of dairy products, and are lower in red and processed meat, sugar, and refined grains. In summary, although low carbohydrate diets appear to be safe and effective in people with diabetes, there are more sustainable alternatives available and this should be fully explained to all those with type 2 diabetes.

\section{ACKNOWLEDGMENTS}

No funding or sponsorship was received for this study or the publication of this article. The named author meets the International Committee of Medical Journal Editors (ICMJE) criteria for authorship for this manuscript, takes responsibility for the integrity of the work as a whole, and has given final approval for the version to be published.
Disclosures. Pamela Dyson declares that she has no conflict of interest.

Compliance with ethics guidelines. This article is based on previously conducted studies, and does not involve any new studies of human or animal subjects conducted by the author.

Open Access. This article is distributed under the terms of the Creative Commons Attribution-NonCommercial 4.0 International License (http://creativecommons.org/licenses/ by-nc/4.0/), which permits any noncommercial use, distribution, and reproduction in any medium, provided you give appropriate credit to the original author(s) and the source, provide a link to the Creative Commons license, and indicate if changes were made.

\section{REFERENCES}

1. Tattersall B. Diabetes: the biography. Oxford: Oxford University Press; 2009.

2. Moran M. The evolution of the nutritional management of diabetes. Proc Nutr Soc. 2004;63:615-20.

3. Sawyer L, Gale EAM. Diet, delusion and diabetes. Diabetologia. 2009;52:1-7.

4. Feinman RD, Pogozelski WK, Astrup A, et al. Dietary carbohydrate restriction as the first approach in diabetes management: critical review and evidence base. Nutrition. 2015;31:1-13.

5. Dyson PA, Kelly T, Deakin T, on behalf of Diabetes UK Nutrition Working Group, et al. Diabetes UK evidence-based nutrition guidelines for the prevention and management of diabetes. Diabet Med. 2011;28:1282-8.

6. Evert $A B$, Boucher JL, Cypress $M$, et al. Nutrition therapy recommendations for the management of adults with diabetes. Diabetes Care. 2014;37:S120-43.

7. Dyson P. A review of low and reduced carbohydrate diets and weight loss in type 2 diabetes. J Hum Nutr Diet. 2008;21:530-8. 
8. Kirk JK, Graves DE, Craven TE, Lipkin EW, Austin M, Margolis KL. Restricted-carbohydrate diets in patients with type 2 diabetes: a meta-analysis. J Am Diet Assoc. 2008;108:91-100.

9. Castañeda-González LM, Bacardí Gascón M, Jiménez Cruz A. Effects of low carbohydrate diets on weight and glycemic control among type 2 diabetes individuals: a systemic review of RCT greater than 12 weeks. Nutr Hosp. 2011;26:1270-6.

10. Naude CE, Schoonees A, Senekal M, Young T, Garner P, Volmink J. Low carbohydrate versus isoenergetic balanced diets for reducing weight and cardiovascular risk: a systematic review and meta-analysis. PLoS One. 2014;9:e100652.

11. VanItallie TB, Nufert TH. Ketones: metabolism's ugly duckling. Nutr Rev. 2003;61:327-41.

12. Adam-Perrot A, Clifton P, Bronus F. Low-carbohydrate diets: nutritional and physiological aspects. Obes Rev. 2006;7(1):49-58.

13. Atkins RC. Dr Atkins new diet revolution. New York: Avon Books, HarperCollins; 2003.

14. Sears B. The zone: a dietary road map. New York: HarperCollins; 1995.

15. Agatston A. The South Beach Diet. New York: St Martin's Press; 2003.

16. Ajala O, English P, Pinkney J. Systematic review and meta-analysis of different dietary approaches to the management of type 2 diabetes. Am J Clin Nutr. 2013;97:505-16.

17. Mann JI, Te Morenga L. Diet and diabetes revisited, yet again. Am J Clin Nutr. 2013;97:453-4.

18. Iqbal N, Vetter ML, Moore RH, et al. Effects of a low-intensity intervention that prescribed a low-carbohydrate vs. a low-fat diet in obese, diabetic participants. Obesity. 2010;18:1733-8.

19. Elhayany A, Lustman A, Abel R, Attal-Singer J, Vinker S. A low carbohydrate Mediterranean diet improves cardiovascular risk factors and diabetes control among overweight patients with type 2 diabetes mellitus: a 1-year prospective randomized intervention study. Diabetes Obes Metab. 2010;12:204-9.

20. Larsen RN, Mann NJ, Maclean E, Shaw JE. The effect of high-protein, low-carbohydrate diets in the treatment of type 2 diabetes: a 12 month randomised controlled trial. Diabetologia. 2011;54:731-40.

21. Guldbrand H, Dizdar B, Bunjaku B, et al. In type 2 diabetes, randomisation to advice to follow a low-carbohydrate diet transiently improves glycaemic control compared with advice to follow a low-fat diet producing a similar weight loss. Diabetologia. 2012;55:2118-27.

22. Krebs JD, Bell D, Hall R, et al. Improvements in glucose metabolism and insulin sensitivity with a low-carbohydrate diet in obese patients with type 2 diabetes. J Am Coll Nutr. 2013;32:11-7.

23. Mayer SB, Jeffreys AS, Olsen MK, McDuffie JR, Feinglos MN, Yancy WS Jr. Two diets with different haemoglobin A1c and antiglycaemic medication effects despite similar weight loss in type 2 diabetes. Diabetes Obes Metab. 2014;16:90-3.

24. Yamada $Y$, Uchida J, Izumi $H$, et al. A non-calorie-restricted low-carbohydrate diet is effective as an alternative therapy for patients with type 2 diabetes. Intern Med. 2014;53:13-9.

25. Tay J, Luscombe-Marsh ND, Thompson $\mathrm{CH}$, et al. A very low-carbohydrate, low-saturated fat diet for type 2 diabetes management: a randomized trial. Diabetes Care. 2014;37:2909-18.

26. Maiorino MI, Petrizzo M, Bellastella G, Giugliano D, Esposito $\mathrm{K}$, et al. Comment on Tay et al. A very low-carbohydrate, low-saturated fat diet for type 2 diabetes management: a randomized trial. Diabetes Care. 2015;38:e64.

27. Tay J, Luscombe-Marsh ND, Thompson $\mathrm{CH}$, et al. Comparison of low- and high-carbohydrate diets for type 2 diabetes management: a randomized trial. Am J Clin Nutr. 2015.doi:10.3945/ajcn.115.112581

28. Wheeler ML, Dunbar SA, Jaacks LM, et al. Macronutrients, food groups, and eating patterns in the management of diabetes: a systematic review of the literature, 2010. Diabetes Care. 2012;35:434-45.

29. Johnston BC, Kanters S, Bandayrel K, et al. Comparison of weight loss among named diet programs in overweight and obese adults: a meta-analysis. JAMA. 2014;312:923-33.

30. Sacks FM, Bray GA, Carey VJ, et al. Comparison of weight-loss diets with different compositions of fat, protein, and carbohydrates. New Engl J Med. 2009;360:859-73.

31. Hite $\mathrm{AH}$, Berkowitz VG, Berkowitz $\mathrm{K}$. Low-carbohydrate diet review: shifting the paradigm. Nutr Clin Pract. 2011;26:300-8.

32. Foresight. Tackling obesities: future choicesproject report. 2nd ed. London: Government Office for Science; 2009.

33. US Department of Agriculture. A series of systematic reviews on the relationship between 
dietary patterns and health outcomes. Alexandria: USDA; 2014.

34. Willett WC, Stampfer MJ. Current evidence on healthy eating. Annu Rev Public Health. 2013;34:77-95.

35. Seal CJ, Brownlee IA. Whole-grain foods and chronic disease: evidence from epidemiological and intervention studies. Proc Nutr Soc. $2015 ; 11: 1-7$.

36. Te Morenga L, Mallard S, Mann J. Dietary sugars and body weight: systematic review and meta-analyses of randomised controlled trials and cohort studies. BMJ. 2013;346:e7492.

37. Malik VS, Pan A, Willett WC, $\mathrm{Hu}$ FB. Sugar-sweetened beverages and weight gain in children and adults: a systematic review and meta-analysis. Am J Clin Nutr. 2013;98:1084-102.

38. O'Connor L, Imamura F, Lentjes MA, Khaw KT, Wareham NJ, Forouhi NG. Prospective associations and population impact of sweet beverage intake and type 2 diabetes, and effects of substitutions with alternative beverages. Diabetologia. 2015;58:1474-83.

39. Xi B, Huang Y, Reilly KH, et al. Sugar-sweetened beverages and risk of hypertension and CVD: a dose-response meta-analysis. $\mathrm{Br} \mathrm{J}$ Nutr. 2015;14(113):709-17.

40. Look AHEAD Research Group, Wing RR, Bolin P, Brancati FL, et al. Cardiovascular effects of intensive lifestyle intervention in type 2 diabetes. N Engl J Med. 2013;369:145-54.

41. Wing RR, Look AHEAD Research Group. Implications of Look AHEAD for clinical trials and clinical practice. Diabetes Obes Metab. 2014;16:1183-91.

42. Raynor HA, Anderson AM, Miller GD, Look AHEAD Research Group, et al. Partial meal replacement plan and quality of the diet at 1 year: action for health in diabetes (Look AHEAD) Trial. J Acad Nutr Diet. 2015;115:731-42.

43. Czyżewska-Majchrzak $€$, Grzelak T, Kramkowska $\mathrm{M}$, Czyżewska K, Witmanowski H. The use of low-carbohydrate diet in type 2 diabetesbenefits and risks. Ann Agric Environ Med. 2014;21:320-6.

44. Noto $\mathrm{H}$, Goto A, Tsujimoto $\mathrm{T}$, Noda $\mathrm{M}$. Low-carbohydrate diets and all-cause mortality: a systematic review and meta-analysis of observational studies. PLoS One. 2013;8:e55030.
45. Whitham D. Nutrition for the prevention and treatment of chronic kidney disease in diabetes. Can J Diabetes. 2014;38:344-8.

46. Tirosh A, Golan R, Harman-Boehm I, et al. Renal function following three distinct weight loss dietary strategies during 2 years of a randomized controlled trial. Diabetes Care. 2013;36:2225-32.

47. Friedman AN, Ogden LG, Foster GD, et al. Comparative effects of low-carbohydrate high-protein versus low-fat diets on the kidney. Clin J Am Soc Nephrol. 2012;7:1103-11.

48. Brinkworth GD, Buckley JD, Noakes M, Clifton PM. Renal function following long-term weight loss in individuals with abdominal obesity on a very-low-carbohydrate diet vs high-carbohydrate diet. J Am Diet Assoc. 2010;110:633-8.

49. Bielohuby $M$, Matsuura $M$, Herbach $N$, et al. Short-term exposure to low-carbohydrate, high-fat diets induces low bone mineral density and reduces bone formation in rats. $\mathrm{J}$ Bone Miner Res. 2010;25:275-84.

50. Reddy ST, Wang CY, Sakhaee K, Brinkley L, Pak CY. Effect of low-carbohydrate high-protein diets on acid-base balance, stone-forming propensity, and calcium metabolism. Am J Kidney Dis. 2002;40:265-74.

51. Carter JD, Vasey FB, Valeriano J. The effect of a low-carbohydrate diet on bone turnover. Osteoporos Int. 2006;17:1398-403.

52. Liebman M. When and why carbohydrate restriction can be a viable option. Nutrition. 2014;30:748-54.

53. Calton J. Prevalence of micronutrient deficiency in popular diet plans. J Int Soc Sports Nutr. 2010;7:24.

54. Gardner CD, Kim S, Bersamin A, et al. Micronutrient quality of weight-loss diets that focus on macronutrients: results from the A TO Z study. Am J Clin Nutr. 2010;92:304-12.

55. Anderson JW, Baird P, Davis RH Jr, et al. Health benefits of dietary fiber. Nutr Rev. 2009;67:188-205.

56. Fardet A, Boirie Y. Associations between food and beverage groups and major diet-related chronic diseases: an exhaustive review of pooled/ meta-analyses and systematic reviews. Nutr Rev. 2014;72:741-62.

57. Chowdhury R, Warnakula S, Kunutsor S, et al. Association of dietary, circulating, and supplement fatty acids with coronary risk: a systematic review 
and meta-analysis. Ann Intern Med. 2014;160:398-406.

58. Harcombe Z, Baker JS, Cooper SM, et al. Evidence from randomised controlled trials did not support the introduction of dietary fat guidelines in 1977 and 1983: a systematic review and meta-analysis. Open Heart. 2015;2:e00196.

59. Willett WC, Stampfer MJ, Sacks FM. Association of dietary, circulating, and supplement fatty acids with coronary risk. Ann Intern Med. 2014;161:453.

60. Mann J, McLean R, Te Morenga L. Evidence favours an association between saturated fat intake and coronary heart disease. BMJ. 2013;347:f6851.

61. United States Department of Health and Human Services and of Agriculture. Scientific report of the 2015 Dietary Guidelines Advisory Committee. USDA; 2015.

62. Hooper L, Martin N, Abdelhamid A, Davey Smith G. Reduction in saturated fat intake for cardiovascular disease. Cochrane Database Syst Rev. 2015;6:CD011737.

63. Schwingshackl L, Hoffmann G. Comparison of effects of long-term low-fat vs high-fat diets on blood lipid levels in overweight or obese patients: a systematic review and meta-analysis. J Acad Nutr Diet. 2013;113:1640-61.

64. FAO. Definition of sustainable diets. International scientific symposium: biodiversity and sustainable diets united against hunger. Rome (Italy): Food and Agriculture Organization of the United Nations; 2010 .

65. Weber CL, Matthews HS. Food-miles and the relative climate impacts of food choices in the United States. Environ Sci Technol. 2008;43:3508-13.

66. Yang W, Lu J, Weng J, for the China National Diabetes and Metabolic Disorders Study Group, et al. Prevalence of diabetes among men and women in China. $\mathrm{N}$ Engl J Med. 2010;362:1090-101.

67. Chan J, Malik V, Jia W, et al. Diabetes in Asia. Epidemiology, risk factors, and pathophysiology. JAMA. 2009;301:2129-40.

68. International Diabetes Federation. Diabetes atlas. 6th ed. Brussels: IDF; 2013. 